\title{
ANÁLISIS SISMOESTRATIGRÁFICO Y SECUENCIAL DEL SECTOR SUR OESTE DE LA CUENCA DE LOS LLANOS ORIENTALES (COLOMBIA)
}

\author{
Fanny Johanna Villamizar'1 ${ }^{1}$ Luis Antonio Castillo²
}

DOI: http://dx.doi.org/10.18273/revbol.v38n3-2016004 (c) (1) Ð

Forma de citar: Villamizar, F.J., y Castillo, L.A. 2016. Análisis sismoestratigráfico y secuencial del sector suroeste de la cuenca de los Llanos Orientales (Colombia). Boletín de Geología, 38(3): 55-69.

\section{RESUMEN}

La cuenca de los Llanos Orientales de Colombia, ha sido estudiada por su potencial exploratorio para la industria del petróleo. Sin embargo, su estudio ha sido netamente litoestratigráfico. Esto reitera el carácter descriptivo, y no interpretativo, y con ello el poco entendimiento estratigráfico del área. Basados en la información sísmica, de pozos y bioestratigrafía, con este trabajo se pretende dar un sentido interpretativo y cronoestratigráfico al intervalo del Oligoceno, basado en herramientas como la estratigrafía de secuencias. Se busca establecer la continuidad de los depósitos del Oligoceno, por lo tanto, la distribución de los cuerpos arenosos y su relación paleoambiental.

Palabras clave: sismoestratigrafía, estratigrafía de secuencias, cronoestratigrafía.

\section{SEQUENTIAL ANALYSIS AND SEISMICSTRATIGRAPHIC OF SOUTH WEST IN THE LLANOS ORIENTALES BASIN (COLOMBIA)}

\begin{abstract}
The Llanos Basin had been studied by their hydrocarbon potential. However, it has been based on lithostratigraphy. And that is completely descriptive and no interpretative. This paper will give a chronostratigraphy interpretation for Oligocene sequences, based on well log information, seismic data and biostratigraphy, integrated with sequential tools. The main target is continuity and paleo-environmental relationships of sandstone bodies.
\end{abstract}

Keywords: seismic-stratigraphy, sequential stratigraphy, chronostratigraphic.

\footnotetext{
${ }^{1}$ Ecopetrol S.A, fjvillamizarm@unal.edu.co

${ }^{2}$ Universidad Nacional de Colombia, lacastillol@unal.edu.co
} 


\section{INTRODUCCIÓN}

En la cuenca de los Llanos Orientales han sido realizado estudios estratigráficos: Bayona et al. (2007); Bayona et al. (2008); Fajardo et al. (2000); Santos et al. (2007) y Sarmiento (2001). En su mayoría son de carácter estructural, con el objetivo de conocer la evolución geológica de la región: Bayona et al. (2007); Bayona et al. (2008); Cooper et al. (1995); Cortés et al. (2006); Gómez et al. (2005); Mora et al. (2006) y Sarmiento (2001). Además, se han llevado a cabo estudios secuenciales regionales como Fajardo et al. (2000), y Reyes (1989) que se enfocó geográficamente al este de la cuenca, donde identifica tres megasecuencias, detallando la megasecuencia Terciaria. Posterior a este estudio Reyes et al. (1998), integraron el análisis ambiental y estratigráfico de pozos, interpretación sísmica, análisis bioestratigráficos y análisis petrofísicos, desde el Cretáceo tardío a Mioceno medio. Estos estudios son de carácter regional. El presente trabajo permite establecer una interpretación con más detalle, y no a escala regional.

\section{LOCALIZACIÓN ÁREA DE ESTUDIO}

El área de estudio comprende una extensión de 800 $\mathrm{km}^{2}$, se localiza cerca al municipio de Puerto Gaitán (departamento del Meta, Colombia), a $300 \mathrm{~km}$ de Bogotá, en el sector centro-este de Colombia, dentro de la cuenca de los Llanos Orientales (FIGURA 1).

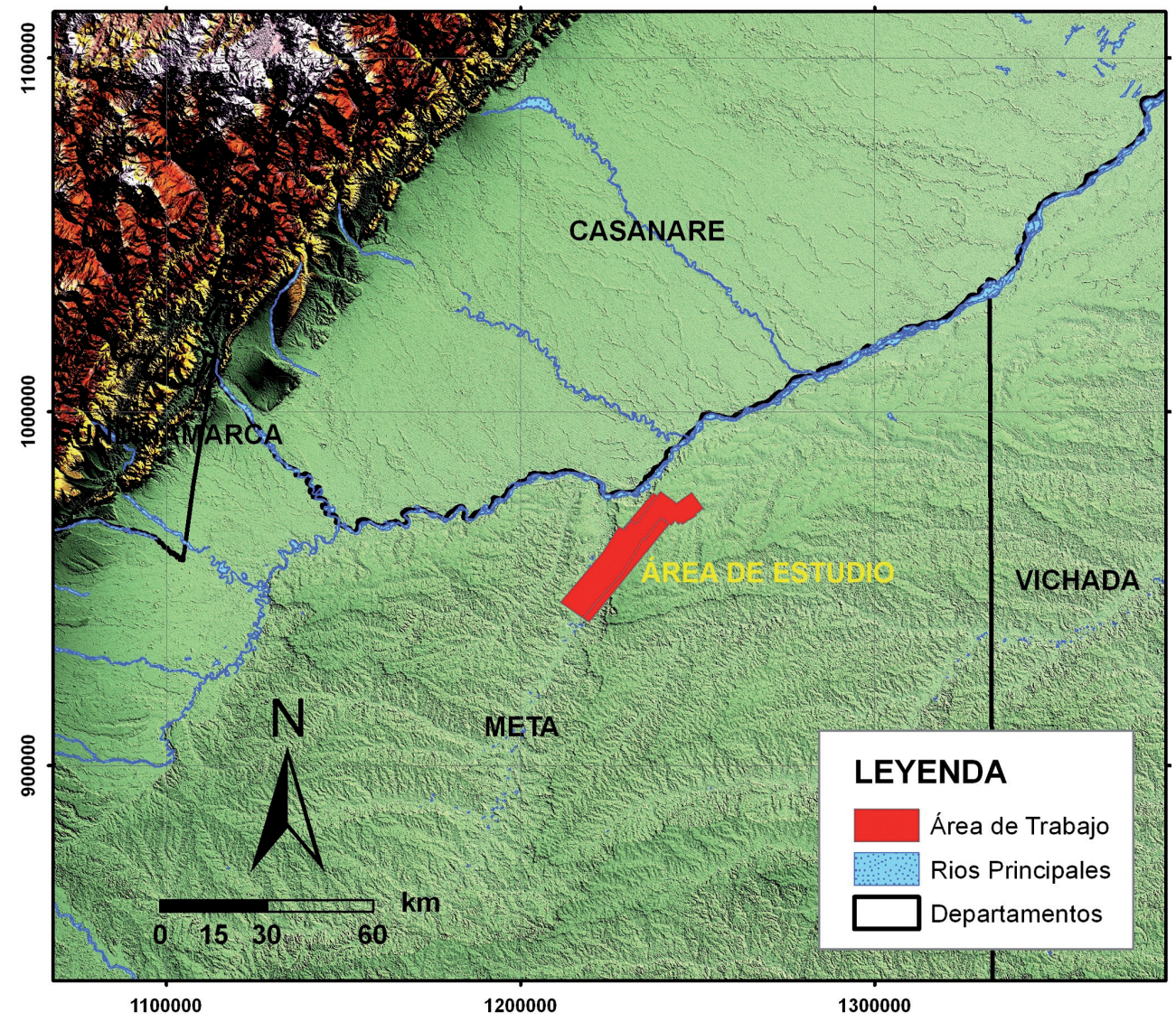

FIGURA 1. Localización área de estudio: cuenca de los Llanos Orientales.

El estudio se basó en $800 \mathrm{~km}^{2}$ de un volumen sísmico preapilado en tiempo (tasa de muestreo de $2 \mathrm{~ms}$, longitud de registro de $4 \mathrm{~s}$ ), 10 pozos con sus registros básicos (Rayo Gamma, Sónico, Resistivo profundo, Factor fotoeléctrico y Densidad), dos de ellos con disparo de chequeo y un pozo con bioestratigrafía.

\section{METODOLOGÍA}

El análisis se basó en el uso de herramientas sismoestratigráficas, esencialmente la aplicación de estratigrafía de secuencias en datos de pozo y sísmica, de acuerdo a la descripción y análisis de las electrofacies (Stuart et al., 2014; Rider, 2002; Jurado, 1989). Se 
definieron superficies de secuencias de tercer orden, tomando como base los patrones de apilado, los ciclos de caída y subida del nivel base y la bioestratigrafía; estas superficies fueron extrapoladas a la sísmica mediante la realización de sismogramas sintéticos y tablas tiempo profundidad. Esta información permite identificar límites de secuencias sísmicas (Vail et al., 1977). Después, se establece las sismofacies, mediante la técnica $\mathrm{AB} / \mathrm{C}$ (Sangree and Widmier, 1977), lo que permitió generar mapas de facies sísmicas, además de mapas estructurales al tope de las secuencias. A partir de la integración de la información, se pudo hacer seguimiento a los cuerpos arenosos del Oligoceno.

\section{ANÁLISIS ESTRATIGRÁFICO}

El análisis estratigráfico incluyó la interpretación electrofacial y sismoestratigráfica.

\section{Análisis de electrofacies}

Se basó en métodos que incluyen la discretización inicial de la información de ripios, muestras de zanja y registros eléctricos (Rider, 2002; Jurado, 1989). Las columnas litológicas de los pozos evidencian la presencia de carbón, shale y areniscas; lo que permitió la correlación secuencial. Establecida la representatividad del material carbonoso en los pozos, se procedió con la definición de las electrofacies a partir de registros Rayo Gama (Stuart et al., 2014), así: arcillolitas y lodolitas con valores mayores a 110 API; limolitas y limolitas arenosas que corresponden a valores entre 90 y 110 API, y las arenas que se identifican con valores de hasta 90 API. Esta clasificación permitió establecer patrones (Serra, 1984), y tomando análogos respectivos (Stuart et al., 2014; Galloway and Hobday, 1983), se determinan elementos arquitecturales (llanura de inundación indiferenciada o de llanura de inundación media y distal, canales primarios, secundarios y terciarios). Las llanuras de inundación indiferenciada y de llanuras de inundación media se interpretan con valores de Rayo Gama mayores de 110 API, con patrón de registro muy variable, y con poca cantidad de arenas, pero alto contenido de limolitas enriquecidas en arcillolitas, que presentan buen contenido de material carbonoso (FIGURA 2a).

Los depósitos de llanura de inundación distal, en los registros se interpretan con valores de Rayo Gama mayores de $110 \mathrm{API}$, con patrón variable y alto contenido de limolitas y arcillolitas, ocasionalmente se presentan niveles de arenas que corresponderían a depósitos de desbordamiento, con presencia de material carbonoso (FIGURA 2b). Los depósitos de canales distributarios primarios, se interpretan con valores de Rayo Gama menores de 90 API, con patrón cilíndrico o en bloque, granodecreciente, presenta superficie erodada hacia la base y con espesores de arenas mayores a 6 m (FIGURA 2c). En los registros, los depósitos de canales distributarios secundarios se interpretan con Rayo Gama menores de 90 API, con patrón cilíndrico o en campana, granodecreciente $\mathrm{y}$ con espesores de arenas no muy gruesos que gradan a materiales finos de llanuras de inundación (FIGURA 2d). Los depósitos de canales distributarios terciarios se interpretan a partir de valores de Rayo Gama menores de 110 API, con patrón aserrado y en campana, granodecreciente y con delgados niveles arenosos que gradan a areniscas limoarcillosas. Si son de gran extensión corresponden a canales maduros con desbordamientos, pero si son cuerpos pequeños estos corresponden a canales inmaduros o depósitos de desbordamiento abruptamente abandonados (FIGURA 2e).

A partir de los datos bioestratigráficos del Pozo-1 (Pérez, 1986), se distinguen diferentes edades basadas en la palinología (TABLA 1).

\section{Análisis secuencial}

Al caracterizar el comportamiento de los ciclos estratigráficos fue posible determinar condiciones de aumentos del nivel base, que en los pozos claramente se identifican como superficies de inundación y de máxima inundación, de la misma forma se evidencian condiciones de disminución del nivel base, que se pueden observar como superficies erosivas o discordantes. Finalmente, ya con las superficies o marcadores establecidos, se determinaron los ciclos estratigráficos y por ende las secuencias estratigráficas (Posamentier and Allen, 1993; Vail et al., 1977), (FIGURA 3).

El marcador ubicado entre la base del Oligoceno y el límite datado bioestratigráficamente como Eoceno tardío, representa el límite de secuencia cercano a los 33,9 Ma.; sobre esta superficie se desarrollan eventos dónde los patrones de sedimentación se muestran progradantes, existiendo una disminución de la relación espacio de Acomodación-Aporte de sedimentos (A/S), correspondiente a un sistema de nivel bajo "LST". El análisis electrofacial sugiere depósitos de canales primarios intercalados con canales secundarios, que hacen transición a depósitos de canales terciarios interdigitados con depósitos de desbordamiento y llanuras de inundación. Esta transición de facies permitió la definición del aumento de la relación $\mathrm{A} / \mathrm{S}$ e incremento del espacio de acomodación, y que se dispone de manera retrogradante hacia el tope representado y limitado por una superficie de máxima inundación (en toda el área), correspondiendo a un sistema transgresivo "TST". El análisis electrofacial, permite establecer materiales finos de llanura de inundación con esporádicos canales terciarios. 


Depósitos de llanura
de inundación
indiferenciada o
Ilanura de inundación
media (con canales
$\quad$ aislados)
- Intercalación de
areniscas, arcillolitasy
enriquecimiento en
material fino.
- Patrón de registro
altamente variable
atribuidos a abanicos de
rotura e inundaciones.

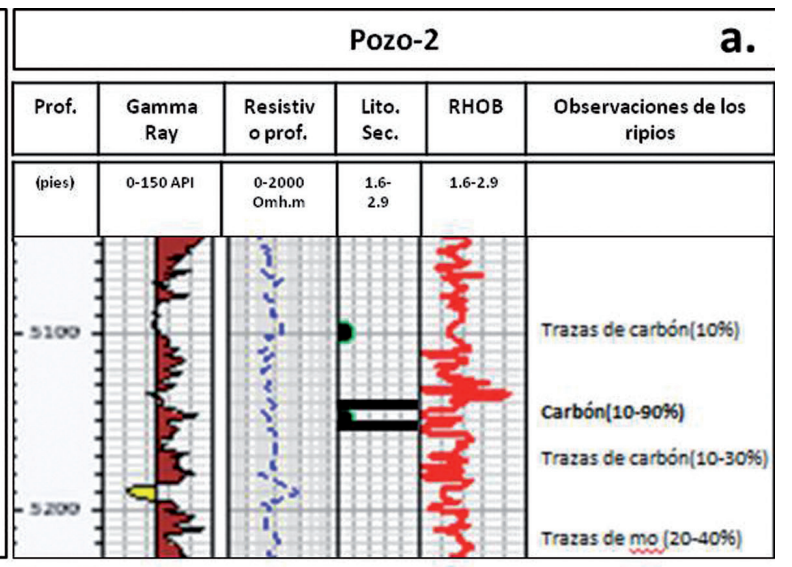

\begin{tabular}{|c|c|c|c|c|c|c|}
\hline \multirow{4}{*}{$\begin{array}{l}\begin{array}{c}\text { Depósitos de Canal } \\
\text { terciario }\end{array} \\
\text { - Areniscas limosas y } \\
\text { arcillosas hacia el tope. } \\
\text { - Patrón de registro } \\
\text { típicamente aserrado y en } \\
\text { campana; } \\
\text { granodecreciente. } \\
\text { - GR }<110 \mathrm{API} \text {. } \\
\text { - Areniscas con espesores } \\
\text { menores a } 3 \text { metros. }\end{array}$} & \multicolumn{6}{|c|}{ Pozo-7 } \\
\hline & Prof. & $\begin{array}{c}\text { Gamma } \\
\text { Ray }\end{array}$ & $\begin{array}{l}\text { Resistiv } \\
\text { oprof. }\end{array}$ & $\begin{array}{l}\text { Lito. } \\
\text { Sec. }\end{array}$ & RHOB & $\begin{array}{l}\text { Observaciones de los } \\
\text { ripios }\end{array}$ \\
\hline & (pies) & 0-150 API & $\begin{array}{l}\text { O-2000 } \\
\text { Omh.m }\end{array}$ & $1.6-2.9$ & $1.6-2.9$ & \\
\hline & 5100 & 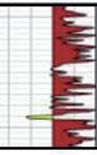 & $\sum_{3}^{k}$ & & & \\
\hline \multirow{4}{*}{$\begin{array}{l}\text { Depósitos de llanura } \\
\text { de inundación distal } \\
\text { - Lodolitas y arcillolitas } \\
\text { laminadas. } \\
\text { - GR generalmente > } 110 \\
\text { API. } \\
\text { - Menor cantidad de } \\
\text { areniscas atribuidas a } \\
\text { abanicos de rotura distal. }\end{array}$} & \multicolumn{6}{|c|}{ Pozo-2 } \\
\hline & Prof. & $\begin{array}{c}\text { Gamma } \\
\text { Ray }\end{array}$ & $\begin{array}{l}\text { Resistiv } \\
\text { oprof. }\end{array}$ & $\begin{array}{l}\text { Lito. } \\
\text { Sec. }\end{array}$ & RHOB & $\begin{array}{l}\text { Observaciones de los } \\
\text { ripios }\end{array}$ \\
\hline & (pies) & $0-150$ API & $\begin{array}{l}\text { O-2000 } \\
\text { Omh.m }\end{array}$ & $1.6-2.9$ & $1.6-2.9$ & \\
\hline & & & $\sum^{3}$ & & & $\begin{array}{l}\text { Trazas de carbón(10\%) } \\
\text { Inclusiones de carbón }\end{array}$ \\
\hline
\end{tabular}

\begin{tabular}{|c|c|c|c|c|c|c|}
\hline \multirow{4}{*}{$\begin{array}{l}\text { Depósitos de Canal } \\
\quad \text { primario } \\
\text { - Patrón de registro en } \\
\text { bloque, con tendencia a } \\
\text { ser granodecreciente. } \\
\text { - GR }<90 \mathrm{API} \text {. } \\
\text { - Areniscas con espesores } \\
\text { mayores a } 6 \text { metros. }\end{array}$} & \multicolumn{6}{|c|}{ Pozo-5 } \\
\hline & Prof. & $\begin{array}{c}\text { Gamma } \\
\text { Ray }\end{array}$ & $\begin{array}{l}\text { Resistiv } \\
\text { oprof. }\end{array}$ & $\begin{array}{l}\text { Lito. } \\
\text { Sec. }\end{array}$ & RHOB & $\begin{array}{l}\text { Observaciones de los } \\
\text { ripios }\end{array}$ \\
\hline & (pies) & 0-150 API & $\begin{array}{l}0-2000 \\
\text { Omh.m }\end{array}$ & $1.6-2.9$ & $1.6-2.9$ & \\
\hline & 5100 & है। & $\xi$ & & & \\
\hline
\end{tabular}

\begin{tabular}{|c|c|c|c|c|c|c|}
\hline Depósitos de Canal & \multicolumn{6}{|c|}{ Pozo-4 } \\
\hline $\begin{array}{l}\text { - Areniscas con base } \\
\text { erosiva. }\end{array}$ & Prof. & $\begin{array}{c}\text { Gamma } \\
\text { Ray }\end{array}$ & $\begin{array}{l}\text { Resistiv } \\
\text { oprof. }\end{array}$ & $\begin{array}{l}\text { Lito. } \\
\text { Sec. }\end{array}$ & RHOB & $\begin{array}{l}\text { Observaciones de los } \\
\text { ripios }\end{array}$ \\
\hline $\begin{array}{l}\text { - Patrón de registro en } \\
\text { bloque o campana y }\end{array}$ & (pies) & $0-150 \mathrm{APl}$ & $\begin{array}{l}0.2000 \\
\text { Omh.m }\end{array}$ & $1.6-2.9$ & $1.6-2.9$ & \\
\hline $\begin{array}{l}\text { granodecreciente. } \\
\text { - GR < } 90 \mathrm{API} \text {. } \\
\text { - Areniscas con espesores } \\
\text { mayores a } 3 \text { metros. }\end{array}$ & 4400 & & $\frac{3}{3}$ & & & \\
\hline
\end{tabular}

FIGURA 2. Esquema de posibles elementos arquitecturales y litológicos: a. de llanuras de inundación indiferenciada; b. llanuras de inundación distal; c. depósitos de canales distributarios primarios; d. canales distributarios secundarios; y e. Depósitos de canales distributarios terciarios. 
TABLA 1. Resumen del Análisis Palinológico realizados al Pozo-1 (Pérez, 1986).

\begin{tabular}{|c|c|c|c|c|c|c|c|}
\hline \multirow[b]{2}{*}{ Edad } & \multirow[b]{2}{*}{$\begin{array}{l}\text { Profundidad } \\
\text { en pies }\end{array}$} & \multirow[b]{2}{*}{ Ambiente Continental } & \multirow[b]{2}{*}{$\begin{array}{c}\text { Ambiente } \\
\text { Transicional }\end{array}$} & \multicolumn{4}{|c|}{ Ambiente Marino } \\
\hline & & & & $\begin{array}{c}\text { Nerítico } \\
\text { Interno } \\
(0-75 \mathrm{~m})\end{array}$ & $\begin{array}{c}\text { Nerítico } \\
\text { Medio } \\
(75-130 \mathrm{~m}) \\
\end{array}$ & $\begin{array}{c}\text { Nerítico } \\
\text { Externo } \\
(130-200 \mathrm{~m})\end{array}$ & $\begin{array}{c}\text { Batial } \\
\text { Superior } \\
(200-350 \mathrm{~m}) \\
\end{array}$ \\
\hline $\begin{array}{l}\text { Mioceno- } \\
\text { Plioceno(?) }\end{array}$ & 2.750 a 2.863 & $\begin{array}{c}\text { Capas continentales } \\
\text { rojizas }\end{array}$ & & & & & \\
\hline $\begin{array}{l}\text { Mioceno temprano } \\
\text { a medio }\end{array}$ & 3.200 a 3.935 & & & $\begin{array}{l}\text { Marino } \\
\text { somero }\end{array}$ & & & \\
\hline Oligoceno & 4.338 a 4.989 & $\begin{array}{l}\text { Llanura de inundación } \\
\text { con canales de arenas }\end{array}$ & & & & & \\
\hline & 4.338 a 5.092 & $\begin{array}{l}\text { Llanura de inundación } \\
\text { con canales de arenas }\end{array}$ & & & & & \\
\hline Eoceno tardío & 5.143 a 5.430 & $\begin{array}{l}\text { Llanura de inundación } \\
\text { con canales de arenas }\end{array}$ & & & & & \\
\hline $\begin{array}{l}\text { Campaniano } \\
\text { temprano- } \\
\text { Santoniano }\end{array}$ & 5.475 a 5.515 & & & $\begin{array}{l}\text { Marino } \\
\text { somero }\end{array}$ & & & \\
\hline
\end{tabular}

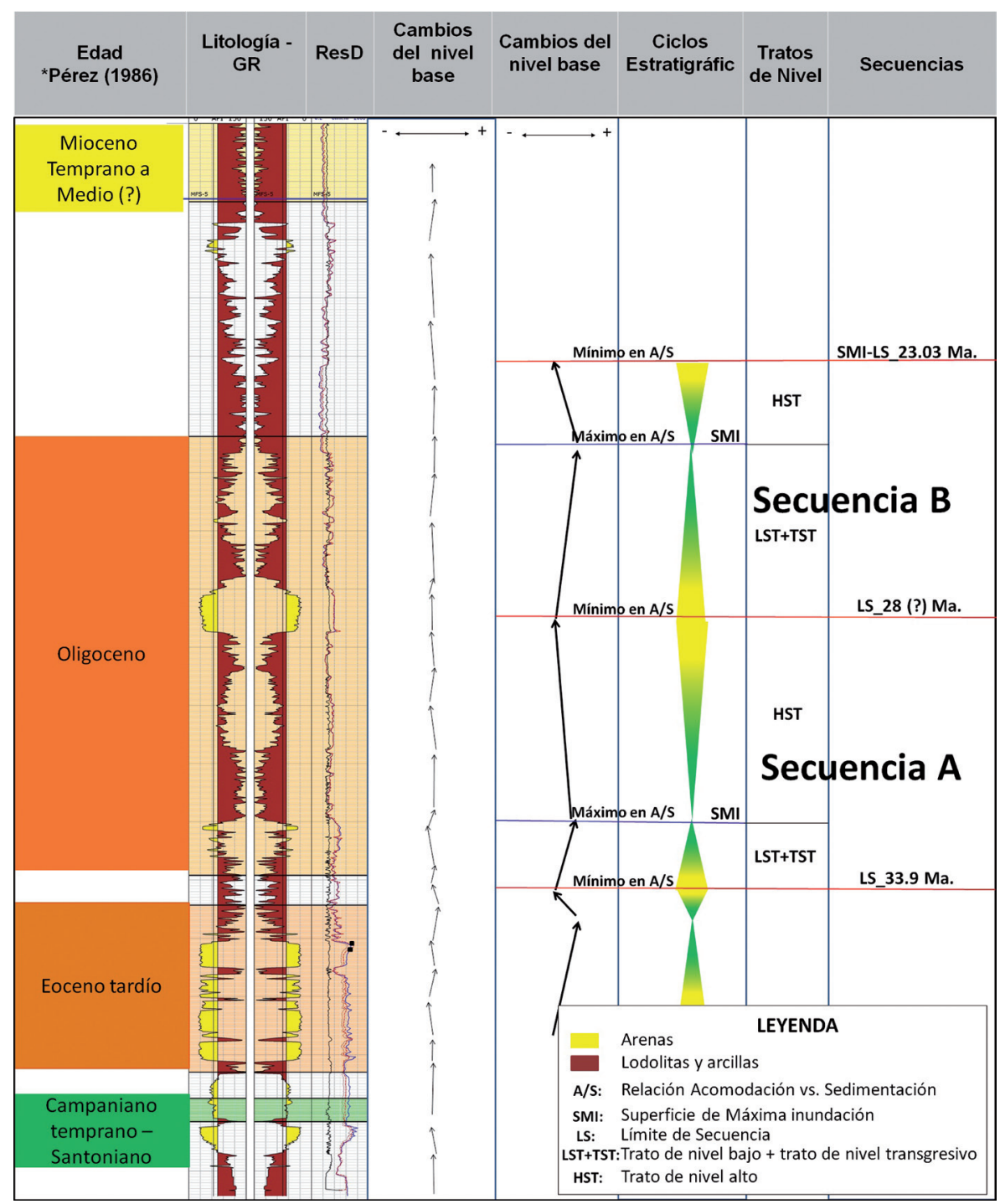

FIGURA 3. Análisis estratigráfico basado en cambios de nivel base aplicado al Pozo-1 del área de estudio. 
Posterior a la transgresión se presenta una disminución en la relación $\mathrm{A} / \mathrm{S}$, limitado hacia la base por una superficie de máxima inundación, y hacia el tope con una superficie discordante, la cual presenta patrones progradantes, correspondientes al sistema de nivel alto "HST". El análisis de electrofacies sugiere interdigitación de algunos canales secundarios con abundantes canales terciarios, que varían lateralmente a depósitos de desbordamiento con llanuras de inundación. De manera aislada se tienen canales primarios hacia el norte del área de estudio.

Después de definir el sistema se identificó un marcador, el cual representa un límite de secuencia cercano a los 28 (?) Ma., superficie en medio del Oligoceno, identificada en todos los pozos estudiados. Sobre ésta superficie discordante se establece una unidad caracterizada por patrones de registros progradantes, producto de la disminución en la relación $\mathrm{A} / \mathrm{S}$, correspondiente a un sistema de nivel bajo "LST". El análisis de electrofacies sugiere una transición de depósitos de canales secundarios y terciarios a complejos de depósitos de desbordamientos y llanuras de inundación. Los canales primarios están presentes hacia el norte del área de estudio.

Después de los episodios anteriores se tiene una mayor relación de A/S, debido al incremento del espacio de acomodación. Esta unidad presenta hacia el tope una superficie de máxima inundación (en toda el área de estudio), hacia su base es con un límite indiferenciado. Los registros presentan patrones retrogradantes (sistema transgresivo). Según el análisis electrofacial corresponden a llanuras de inundación.

Finalmente, se evidencia una nueva disminución en la relación $\mathrm{A} / \mathrm{S}$, donde a la base se encuentra una superficie de máxima inundación, y hacia el tope una inconformidad. Esta última representa el límite de secuencia cercano a los 23,03 Ma, definido por el cambio de ciclo estratigráfico, y a la cercanía del límite Oligoceno con el intervalo datado como Mioceno temprano a medio (?). Este evento presenta patrones progradantes (sistema de nivel alto, "HST"), que junto el análisis de electrofacies, sugiere una transición de llanuras de inundación a depósitos de desbordamiento interdigitados, con esporádicos canales terciarios y de manera aislada canales primarios, intercalados con secundarios hacia el centro del área de estudio (FIGURA 4).

La correlación estratigráfica general (FIGURA 4), se considera como guía para hacer las correlaciones estratigráficas detalladas correspondientes al Oligoceno con direcciones NW a SE y W a E (FIGURA 5 y 6). Para dichas correlaciones se consideró como datum de referencia estratigráfico la superficie de inundación del Mioceno inferior (evento identificado en el área).

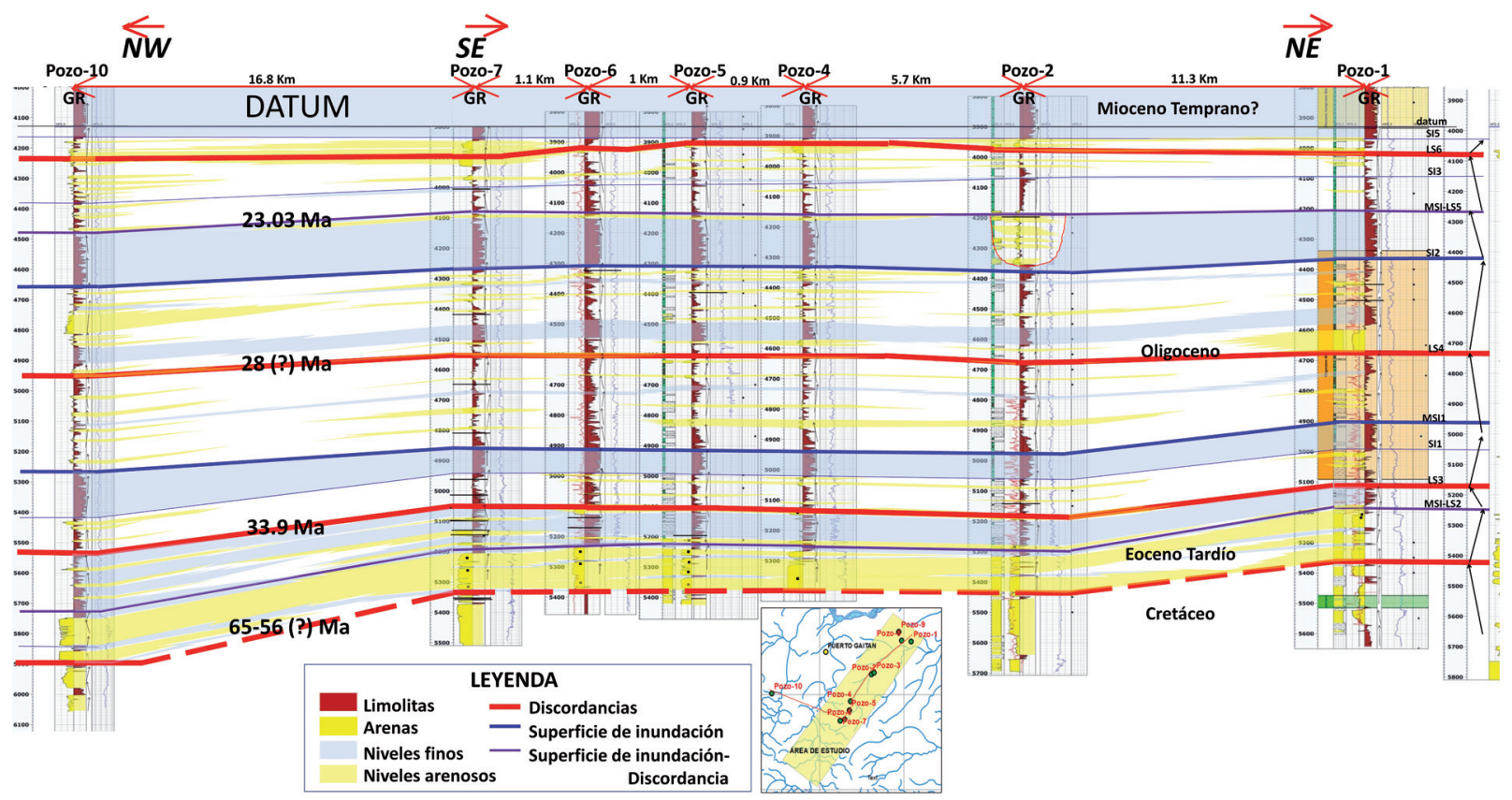

FIGURA 4. Correlación estratigráfica general suroeste-noreste basada en estratigrafía de secuencias. 


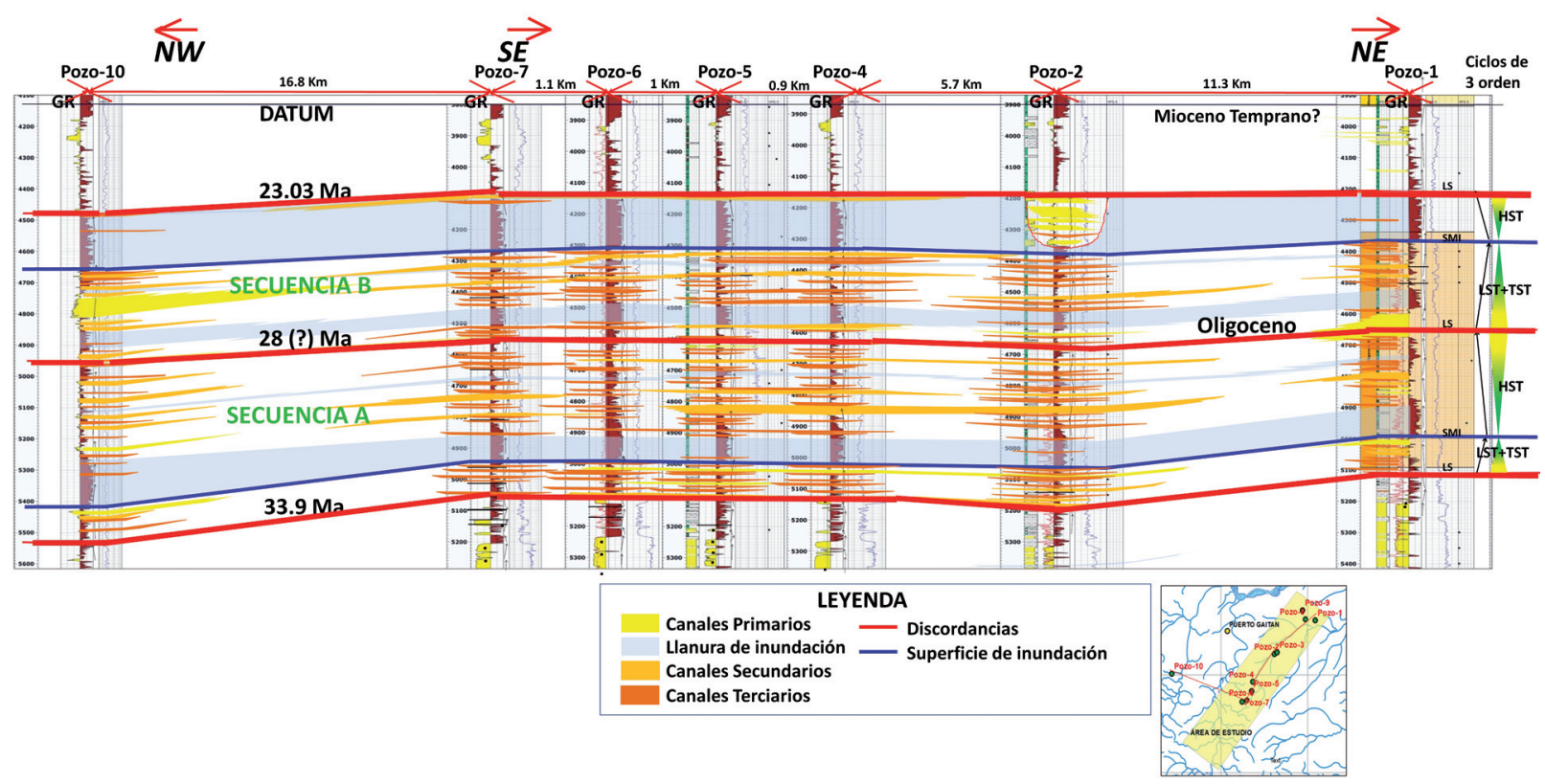

FIGURA 5. Correlación estratigráfica detallada suroeste-noreste basada en estratigrafía de secuencias para el intervalo Oligoceno.
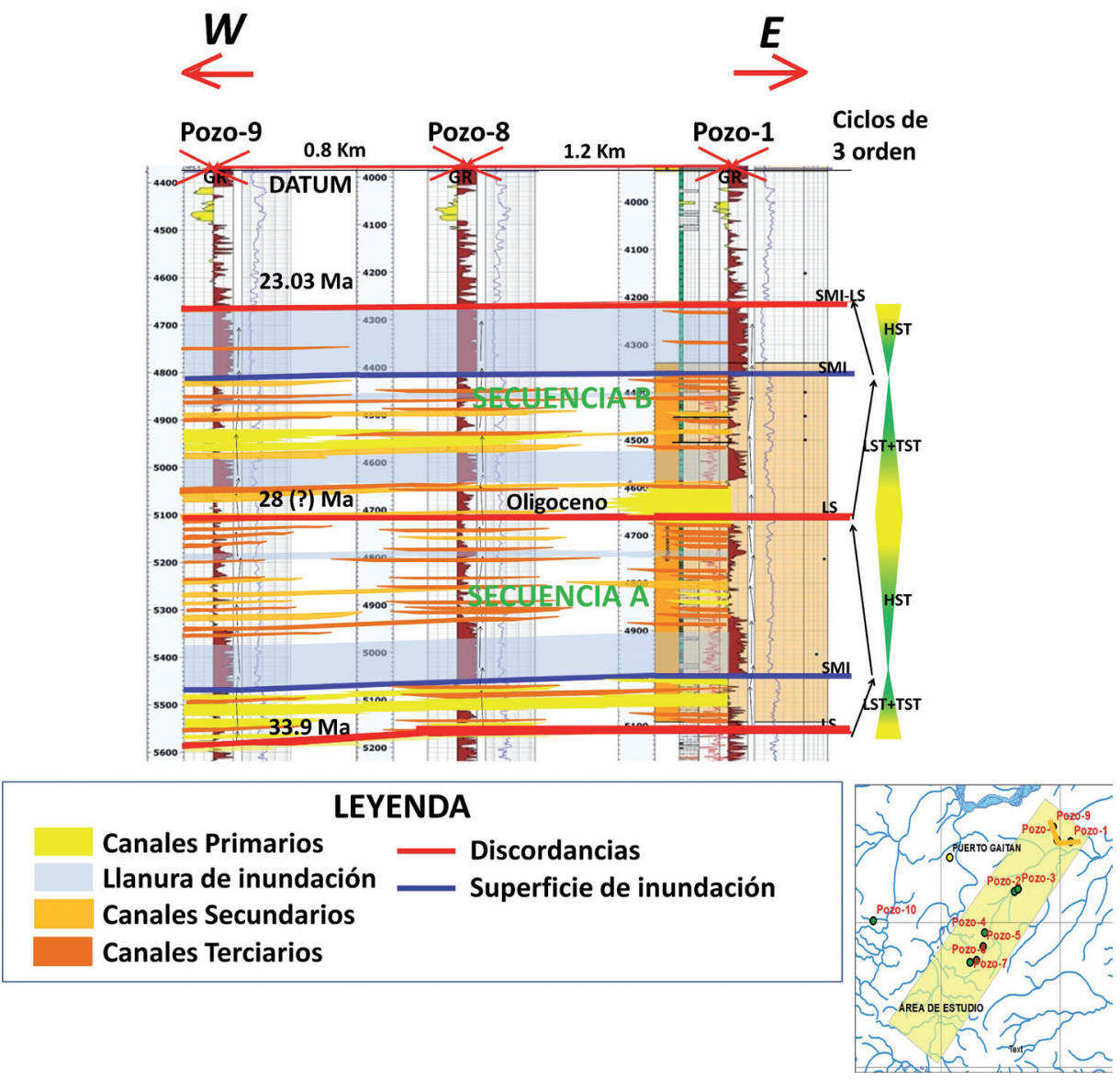

FIGURA 6. Correlación secuencial oeste-este de los pozos 9,8 y 1. 


\section{Estratigrafía sísmica}

La evaluación sismoestratigráfica integra las electrofacies con la información sísmica a partir de la calibración de los pozos a la sísmica, mediante la creación de sismogramas sintéticos, útiles a su vez, para la generación de tablas tiempo profundidad de los pozos que no cuentan con disparos de chequeo, permitiendo la extrapolación de datos bioestratigráficos a la sísmica y representados en zonas sombreadas, considerando los marcadores establecidos anteriormente (FIGURA 7).

Posterior a la conversión se realiza la interpretación sismoestratigráfica con base en herramientas como la estratigrafía de secuencias y las características sísmicas (Vail et al., 1977; Mitchum et al., 1977; Sangree and Widmier, 1977), lo que permitió interpretar dos secuencias y tres horizontes sísmicos para el intervalo Oligoceno (FIGURA 8). La correlación está soportada cronoestratigráficamente por los análisis bioestratigráficos del Pozo 1, según Pérez (1986).

En general, se observa que las secuencias deposicionales tienen un leve aumento de espesor hacia el oeste de la cuenca, hecho coincidente con el depocentro de la misma. A continuación, se describen para el área cada una de las secuencias sísmicas interpretadas para el Oligoceno.

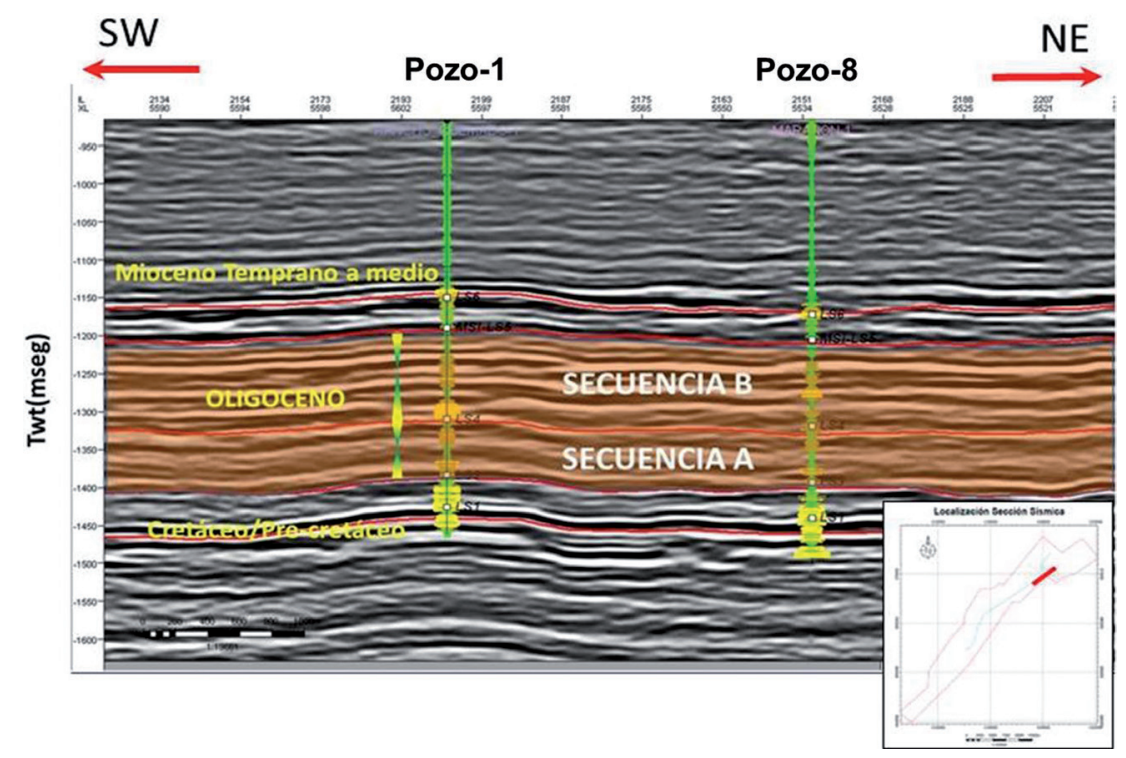

FIGURA 7. Calibración de los pozos a la sísmica, a partir de la generación de sismogramas sintéticos y tablas tiempo profundidad. Extrapolación de datos bioestratigráficos a la sísmica y representados en zonas sombreadas.

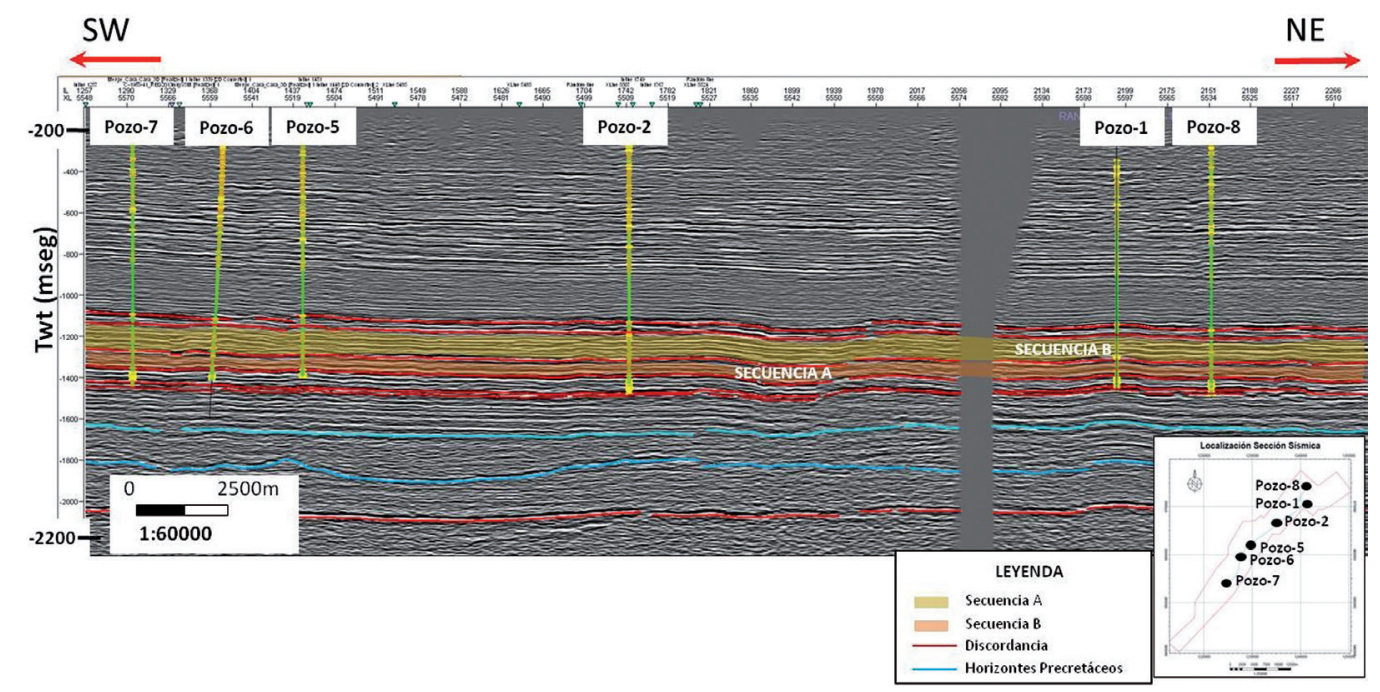

FIGURA 8. Secuencias sísmicas identificadas en el área de estudio, sección sísmica en dirección noreste. 


\section{Secuencia A}

Se caracteriza por espesores moderadamente constantes. El horizonte base corresponde al límite de secuencia de los 33,9 Ma; sus terminaciones son concordantes, mientras que las terminaciones hacia el tope de la secuencia son truncamientos y ocasionalmente son concordantes. El horizonte hacia el tope se encuentra cercano al límite de secuencia de los 28(?) Ma. En esta secuencia el análisis de las facies sísmicas (Sangree and Widmier, 1977) se caracteriza por presentar reflexiones internas con bajas amplitudes, moderadas a bajas frecuencias y un patrón interno de reflexión ondulosa (FIGURA 9).
Las sismofacies T-C/Ond (FIGURA 10) contiene reflexiones con amplitudes moderadamente altas, coincidentes con cuerpos arenosos que progradan hacia el noroeste; ambientalmente corresponden a canales secundarios y terciaros, intercalados con cuerpos más continuos, asociados a llanuras de inundación, representados con reflexiones de bajas amplitudes oscuras, en zonas con baja resolución. La sismofacies C-C/Ond (FIGURA 10) contiene reflexiones de amplitudes medias a bajas, que coinciden con llanuras de inundación. Sin embargo, la resolución de la sísmica (40 m) no permite identificar canales secundarios y terciarios, como se muestran en los pozos.

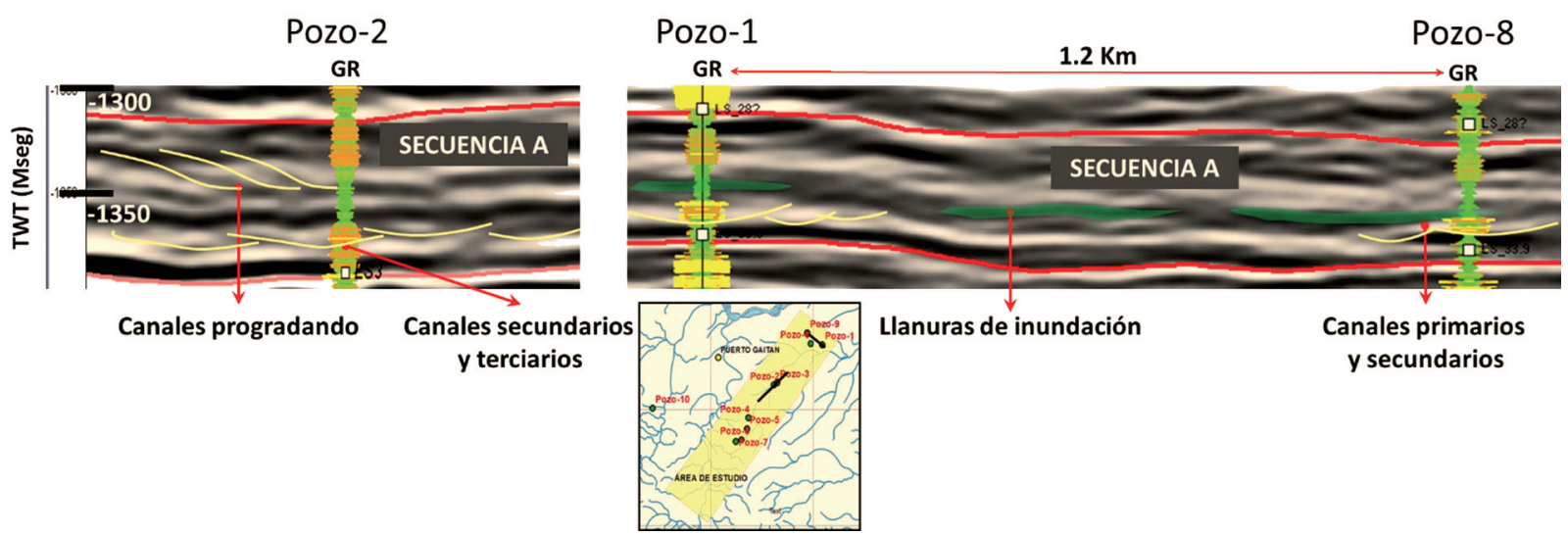

FIGURA 9. Análisis de facies sísmicas en la Secuencia A.

\begin{tabular}{|c|c|c|c|c|}
\hline Secuencia & Sismofacies & Configuración interna & Patrón interno & Ejemplo \\
\hline \multirow[t]{2}{*}{ SECUENCIA A } & T-C/Ond. & $\begin{array}{l}\text { Amplitud: Moderada. } \\
\text { Discontinua con frecuencia } \\
\text { moderada. }\end{array}$ & Onduloso & $\begin{array}{l}\text { En la Figura 13, ésta sismofacies se } \\
\text { distribuye hacia centro del área y con } \\
\text { dirección Noreste, correspondiendo a áreas } \\
\text { con influencia de canales. }\end{array}$ \\
\hline & C-C/Ond & $\begin{array}{l}\text { Amplitud: Moderada a baja. } \\
\text { Discontinuos con frecuencia } \\
\text { baja. }\end{array}$ & Onduloso & $\begin{array}{l}\text { En la Figura 13, ésta sismofacies se } \\
\text { distribuye de manera homogénea hacia los } \\
\text { lados del área, correspondiendo a áreas de } \\
\text { llanura de inundación. }\end{array}$ \\
\hline
\end{tabular}

FIGURA 10. Tipos de facies sísmicas encontradas en la Secuencia A. 


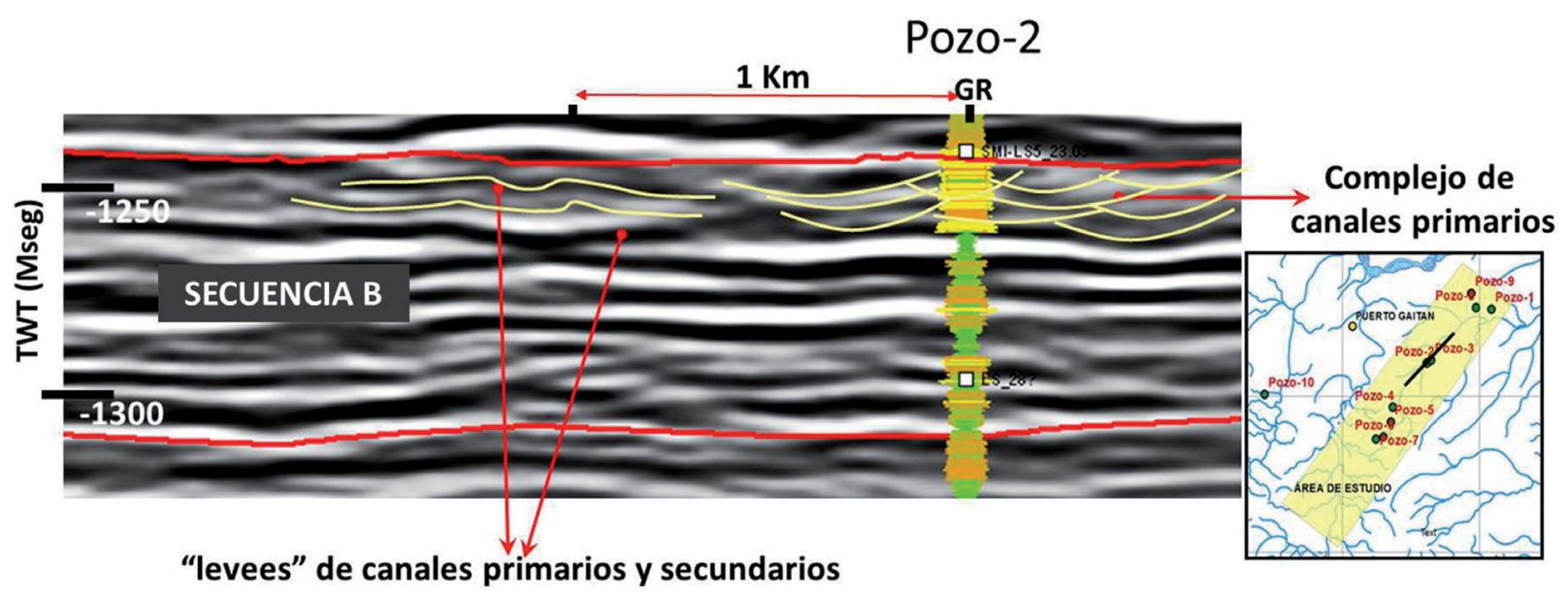

FIGURA 11. Análisis de facies sísmicas en la Secuencia B.

\begin{tabular}{|c|c|c|c|c|}
\hline Secuencia & Sismofacies & Configuración interna & Patrón interno & Ejemplo \\
\hline \multirow[b]{2}{*}{ SECUENCIA B } & C-C/P a Subp & $\begin{array}{l}\text { Amplitud: Alta. } \\
\text { Continua con frecuencia Alta }\end{array}$ & $\begin{array}{l}\text { Paralelo a } \\
\text { subparalelo }\end{array}$ & $\begin{array}{l}\text { En la Figura 13, ésta sismofacie se } \\
\text { distribuye hacia el norte y sur del área. } \\
\text { Ccorresponde a áreas con influencia de } \\
\text { canales indiferenciados, intercalados con } \\
\text { posibles llanuras de inundación. }\end{array}$ \\
\hline & T-C/P a Subp & $\begin{array}{l}\text { Amplitud: Alta pero Variable. } \\
\text { Continua con frecuencia } \\
\text { moderada a Alta }\end{array}$ & $\begin{array}{l}\text { Paralelo a } \\
\text { subparalelo }\end{array}$ & $\begin{array}{l}\text { En la Figura 13, ésta sismofacie se } \\
\text { distribuye hacia el centro y Noroeste del } \\
\text { área, correspondiendo a áreas con } \\
\text { influencia de canales primarios y } \\
\text { secundarios que progradan hacia } \\
\text { noroeste. }\end{array}$ \\
\hline
\end{tabular}

FIGURA 12. Tipos de facies sísmicas encontradas en la Secuencia B.

\section{Secuencia B}

Secuencia caracterizada por espesores constantes a lo largo del área de estudio. El horizonte base se encuentra cercano al límite de secuencia (28? $\mathrm{Ma}$ ), cuyas terminaciones hacia la base son de tipo concordante, mientras hacia el tope de la secuencia son truncamientos y a veces concordantes (FIGURA $11 \mathrm{y}$ 12). El horizonte delimitador se encuentra cercano al límite de secuencia de los 23,03 Ma. Esta secuencia se caracteriza por presentar reflexiones internas cuyas amplitudes y frecuencias resultan ser altas a variables, su patrón interno de reflexión es paralelo a subparalelo (Sangree and Widmier, 1977). El resultado de mapear las distintas sismofacies, deja entrever la distribución de los distintos geocuerpos a nivel regional (FIGURA 13). 

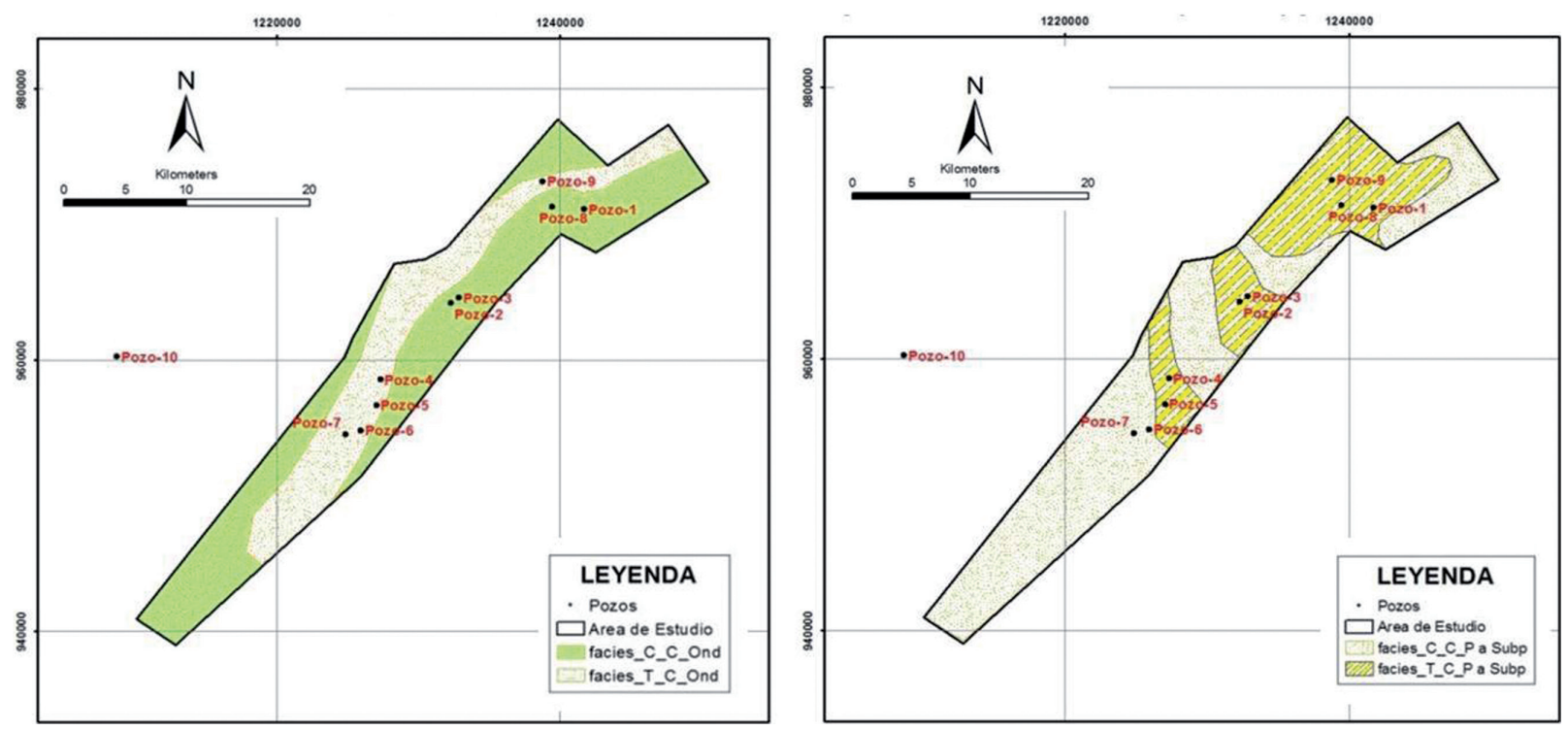

FIGURA 13. Mapa de las distintas facies sísmicas (A/B-C) para la Secuencia A (izquierda) y la Secuencia B (derecha), mostrando su distribución en el área de estudio.

\section{INTEGRACIÓN DE RESULTADOS}

Con el modelo secuencial ya determinado se hace posible generar mapas de distribución de arenas para el Oligoceno, además de hacer la integración de la información ya analizada previamente. La secuencia A corresponde a sistemas de nivel bajo y de nivel alto, respectivamente, mientras la parte media se presenta una superficie de máxima inundación. Distalmente se tienen facies de llanura de inundación, eventos característicos del sistema transgresivo "TST", cuya importancia por su espesor y continuidad es su potencialidad como sello para trampas de hidrocarburos. Hacia la base de esta secuencia se tienen depósitos de desbordamiento y llanuras de inundación. Al centro y norte del área se tienen localmente cuerpos arenosos asociados a canales primarios y secundarios, sinuosos e intermitentes que van en dirección norte, con predominio de canales distributarios terciarios (FIGURA 14). El cambio lateral de facies y el contenido de material arcilloso es alto, lo que compromete la conectividad y continuidad de los canales. Esto evidencia las bajas amplitudes de los atributos sísmicos, correspondiente a llanuras de inundación y depósitos de desbordamiento, lo que confirma los ambientes sedimentarios reportados en los análisis palinológicos en el área, y por ende a un sistema de nivel bajo.
Hacia el tope de la secuencia, centro del área de estudio, los pozos presentan alto contenido de canales distributarios terciarios, intercalados con algunos canales secundarios, pertenecientes al sistema de nivel alto (FIGURA 15). En el resto del área se presenta dominio de material fino y variación lateral, en depósitos de llanuras de inundación proximal y depósitos de desbordamiento.

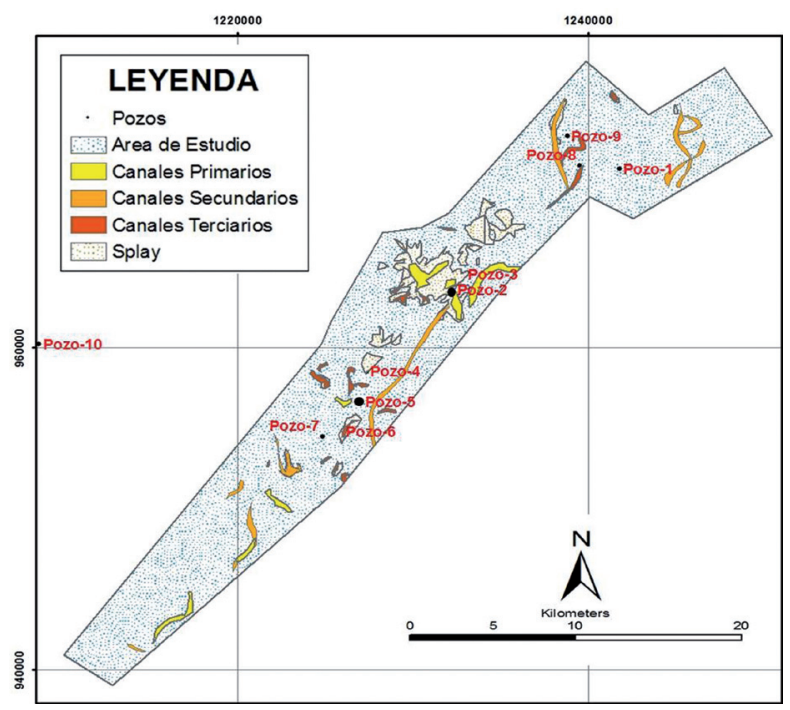

FIGURA 14. Mapa de distribución de arenas al tope de la secuencia A (intervalo más arenoso). 


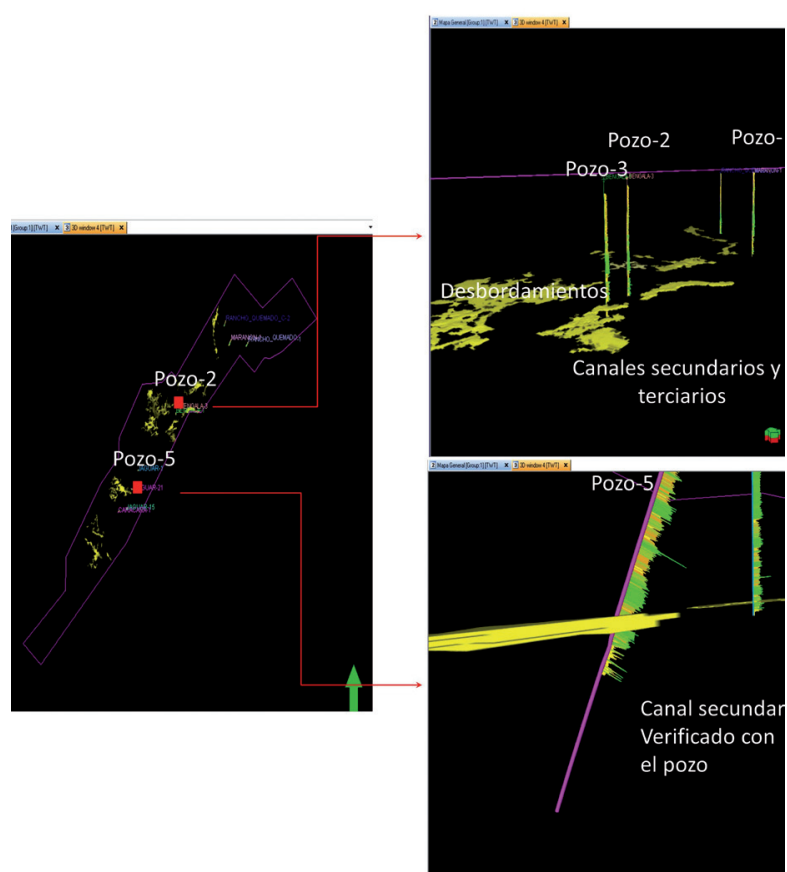

FIGURA 15. Mapa de distribución de arenas al tope de la Secuencia A (28? Ma).

La secuencia B es la más reciente del Oligoceno, en el área de estudio se muestra mucho más arenosa en comparación a la secuencia infrayacente (A). Esta secuencia se compone del sistema de nivel bajo, con cuerpos arenosos muy bien definidos. Estos cuerpos corresponden a complejos de canales primarios y secundarios, algunos tienden a ser rectilíneos y otros divagan de manera sinuosa en dirección norte o noreste. Llanuras de inundación con interdigitación de canales distributarios terciarios se observan en los pozos. Esta sección de la secuencia tiene mejor conectividad y continuidad (FIGURA 16).

Hacia la parte media a superior de la secuencia se tiene una superficie de máxima inundación diferenciable en los pozos y en la sísmica (sistema transgresivo). En los niveles superiores de la secuencia se revela un complejo de canales primarios y secundarios bien localizados, que en la sísmica se advierte como barras progradantes en dirección norte, las cuales corresponde a eventos de un sistema de nivel alto (FIGURA 17).

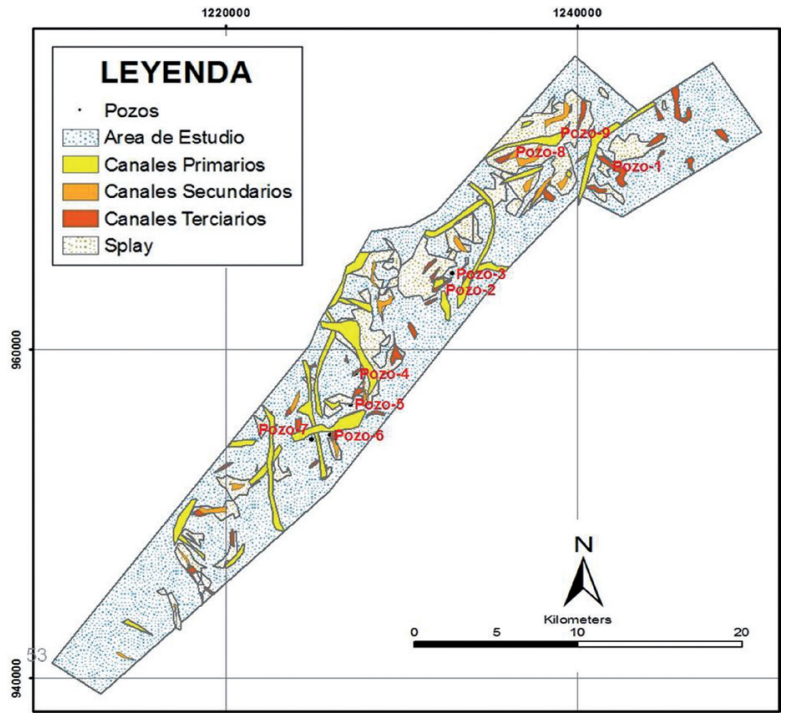

FIGURA 16. Mapa de distribución de arenas al tope de la secuencia B (intervalo más arenoso).

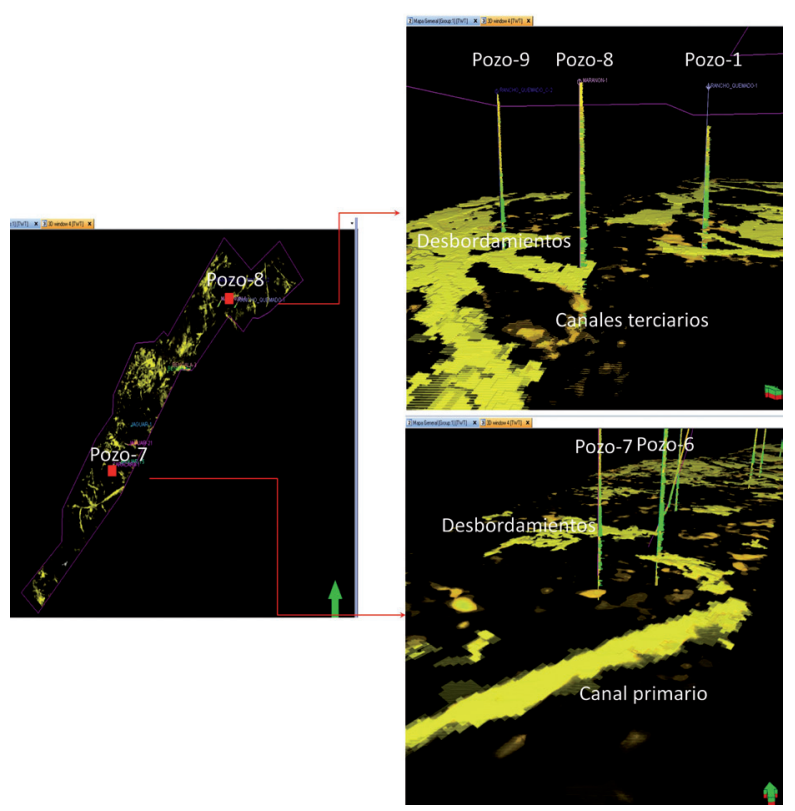

FIGURA 17. Mapa de distribución de arenas al tope de la Secuencia B (23,03 Ma).

A partir de la información analizada estratigráficamente y que incorpora los diferentes ambientes de depósito (FIGURA 18), se presenta un modelo tridimensional con ambientes de depósito similares al del área de estudio, soportado por algunos análogos (Stuart et al., 2014), (FIGURA 19). 


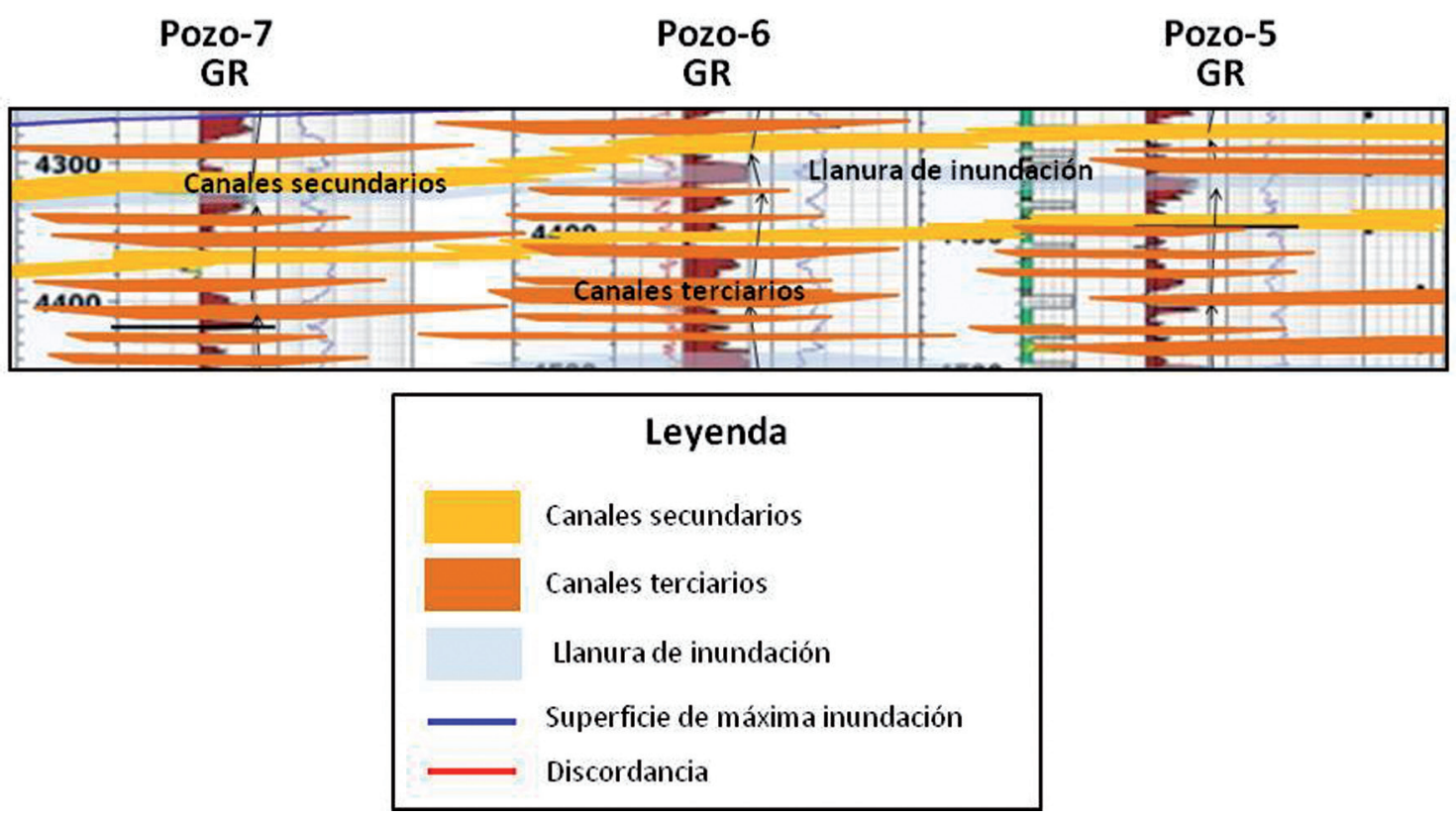

FIGURA 18. Esquema de posibles elementos arquitecturales y litológicos de complejos de canal con depósitos de llanura de inundación.

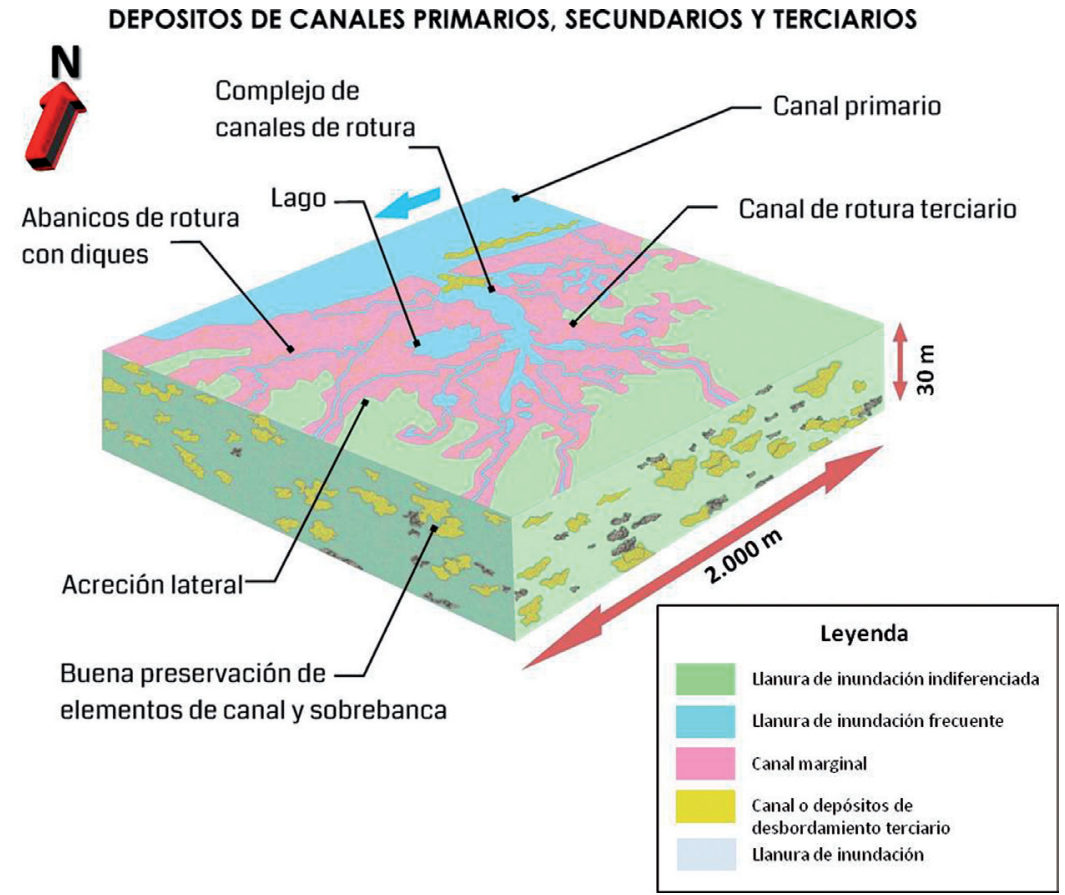

FIGURA 19. Modelo tridimensional análogo con ambientes de depósito similares al del área de estudio, soportado por algunos análogos (Stuart et al., 2014), y que contienen la mayoría de análisis estratigráficos realizados en éste trabajo. 


\section{AGRADECIMIENTOS}

Agradecemos a Ecopetrol SA, por permitir el acceso a la información. Un especial reconocimiento a Crelia Padrón (Universidad Simón Bolívar, Venezuela) y Felipe Lamus Ochoa (Corporación Geológica ARES) por los valiosos aportes que permitieron mejorar el presente manuscrito.

\section{REFERENCIAS}

Bayona, G., Jaramillo, C., Rueda, M., Reyes-Harker, A., and Torres, V. 2007. Paleocene-Middle Miocene flexural-margin migration of the non-marine Llanos foreland basin of Colombia. CTyF Ciencia, Tecnología y Futuro, 3(3): 141-160.

Bayona, G., Cortés, M., Jaramillo, C., Ojeda, G., Aristizabal, J., and Reyes-Harker, A. 2008. An integrated analysis of an orogen-sedimentary basin pair: Latest Cretáceous-Cenozoic evolution of the linked Eastern Cordillera Orogen and the Llanos foreland basin of Colombia. Geological Society of America Bulletin, 120: 1171-1197.

Cooper, M. A., Addison, F.T., Alvarez, R., Coral, M., Graham, R.H., Hayward, A. B., Howe, S., Martínez, J., Naar, J., Peñas. R., Pulham, A. J., and Taborda, A. 1995. Basin development and tectonic history of the Llanos basin, Eastern Cordillera, and middle Magdalena Valley, Colombia. America Association of Petroleum Geologists, 79(10): 1421-1443.

Cortés, M., Bayona, G., Aristizabal, J., Ojeda, G., Reyes Harker, A., and Gamba, N. 2006. Structure and kinematics of the eastern foothills of the eastern cordillera Of Colombia from balanced cross-sections and forward modelling. Simposio Bolivariano Exploracion Petrolera en las Cuencas Subandinas, Cartagena, Colombia, pp. 14.

Fajardo, A., Rojas, E., Cristancho, J., y Consorcio GyG, Going System, L. 2000. Definición del modelo estratigráfico en el intervalo Cretáceo tardío a Mioceno medio en la Cuenca Llanos Orientales y Piedemonte Llanero. Ecopetrol S.A. Instituto Colombiano del Petróleo (ICP), Piedecuesta, 126p.

Galloway, W., and Hobday, D. 1983. Terrigenous clastic depositional systems: Applications to petroleum, Coal, and Uranium Exploration. Editorial Springer-Verlag. New York, 141p.
Gómez, E., Jordan, T., Allmendinger, R.W., and Cardozo, N. 2005. Development of the Colombian foreland-basin system as a consequence of diachronous exhumation of the northern Andes. Geological Society of America Bulletin, 117 (9-10): 1272-1292.

Jurado, M. J. 1989. Diagrafías: su aplicación en el análisis sedimentario. Revista Sociedad Geológica de España, 2 (3-4): 291-301.

Mitchum, R., Vail, P., and Thompson, S. 1977. The depositional sequence as a basic unit for stratigraphic analysis - Applications to hydrocarbon exploration. America Association of Petroleum Geologists Bulletin, 26: 53-62.

Mora, A., Parra, M., Strecker, M.R., Kammer, A., Dimate, C., and Rodríguez, F. 2006. Cenozoic contractional reactivation of Mesozoic extensional structures in the Eastern Cordillera of Colombia. Tectonics, 25: 1-19.

Pérez, G. 1986. Chevron Petroleum Company of Colombia. Pozo-1 San Pedro de Arimena Association contract Final Report, Bogotá.

Posamentier, H.W., and Allen, G. P. 1993. Siliciclastic sequence stratigraphic patterns in foreland ramp-type basins. Geology, 21: 455-458.

Reyes, J. 1989. Estratigrafía de secuencias y potenciales trampas estratigráficas en el área del Meta-Llanos Orientales de Colombia. Ecopetrol S.A. - Instituto Colombiano del Petróleo (ICP), Piedecuesta.

Reyes, J., Fajardo, A., Rubiano, J., Munar, F., Pérez, H., Sandoval, J., Soto, C., Hernández, O. y Rojas, L. 1998. Evaluación Regional Meta. Ecopetrol S.A. - Instituto Colombiano del Petróleo (ICP), Piedecuesta.

Rider, M. 2002. The geological interpretation of well logs. ( $2^{\mathrm{a}}$ ed.). Rider-French Consulting Ltd., Scotland, 280p.

Sangree, J., and Widmier, J. 1977. Seismic interpretation of clastic depositional facies: Seismic Stratigraphy Applications to hydrocarbon exploration. America Association of Petroleum Geologists Bulletin, 26: 165-184.

Santos, C., Jaramillo, C., Torres, V., Rueda, M., Flórez, P., y Rodríguez, G. 2007. Influencia marina en el Eoceno tardío del oriente y suroriente de Colombia. Boletín de Geología, 29(2): 57-65. 
Sarmiento, L.F. 2001. Mesozoic rifting and Cenozoic basin inversion history of the Eastern Cordillera, Colombian Andes, Inferences from tectonic models. Tesis de Doctorado. Netherlands research, School of Sedimentary Geology.

Serra, O. 1984. Análisis de ambientes sedimentarios mediante perfiles de pozo. Editorial Caracas Schlumberger. Venezuela, 272p.

Stuart, J., Mountney, N., Mccaffrey, W., Lang, S., and Collinson, J. 2014. Prediction of channel connectivity and fluvial style in the flood-basin successions of the Upper Permian Rangal Coal measures (Queensland). America Association of Petroleum Geologists Bulletin, 98(2): 191-212.

Vail, P.R., Mitchum, Jr. R.M., and Thompson III, S. 1977. Stages of sea level from coastal "onlap": Seismic Stratigraphy - Applications to hydrocarbon exploration. America Association of Petroleum Geologists Bulletin, 26: 63-81.

Trabajo recibido: julio 3 de 2015

Trabajo aceptado: febrero 19 de 2016

Manuscrito publicado en internet: febrero 25 de 2016 